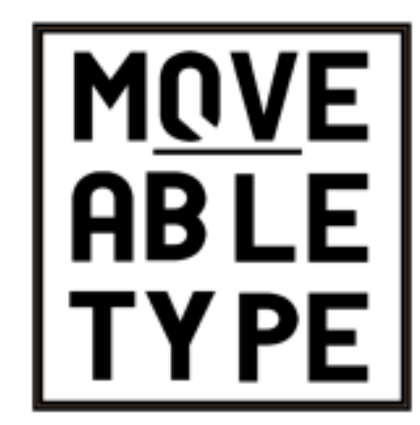

Editor's Foreword: 'Decadence'

Author[s]: Sarah-Jean Zubair

Source: Moveable Type, Vol.11, 'Decadence' (2019)

DOI: $10.14324 / 111.1755-4527.094$

MoveableType is a Graduate, Peer-Reviewed Journal based in the Department of English at UCL.

(C) 2019 Sarah-Jean Zubair. This is an Open Access article distributed under the terms of the Creative Commons Attribution License (CC-BY) 4.0https://creativecommons.org/licenses/by/4.0/, which permits unrestricted use, distribution, and reproduction in any medium, provided the original author and source are credited. 


\section{Editor's Foreword}

$\Psi_{\text {'decline', decadence has }}^{\text {rom a neutral term for }}$

transformed over the centuries into

a laden term invoked to

signify decay, as well as a warning

against the dangers of excess and

the pursuit of pleasure. Perceived

as a disruptive force, dangerous to

social order and bourgeois

normativity, the threat of

decadence is invoked in modern

political rhetoric to stoke anxieties

over shifts in traditional values and

social mores, as well as the looming

threat of an irretrievable loss of

geopolitical power. Yet in spite of

the term's connotations, an

identifiable decadent ethos has

been embraced by writers, artists,

and 'othered' individuals as modes

of aesthetic expression, as well as

rebellion against and liberation

from social strictures. Unlike the

Romantic sublime, wherein the

material self is abandoned in an

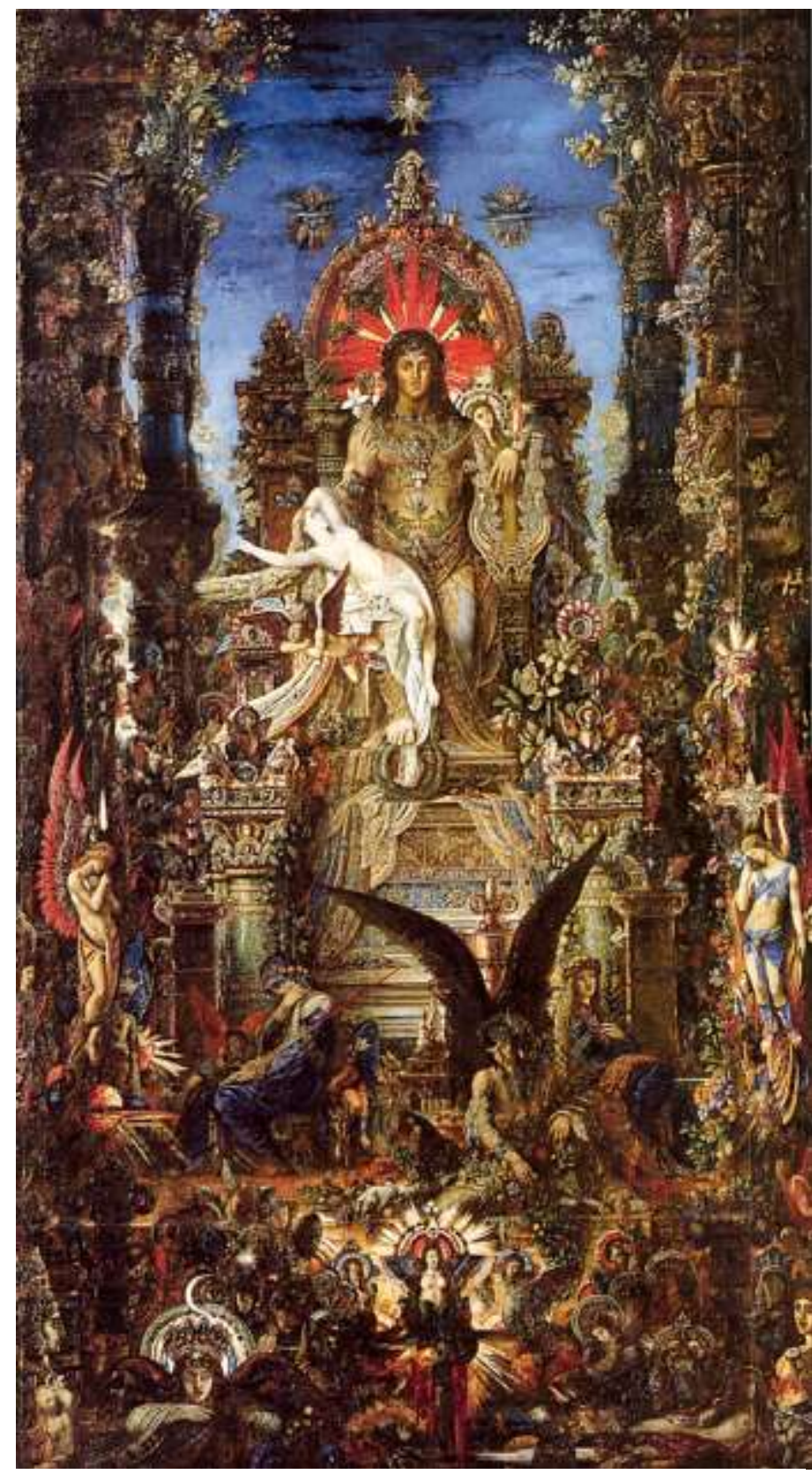

Gustave Moreau, Jupiter and Semele, c. 1894-95, oil on canvas, Musée National Gustave-Moreau. Paris. upward sweep of simultaneous ecstasy and terror, the decadent sublime embraces the downward plunge into materiality. It is this inverse sublime that theorists such as Georges Bataille discuss as an expérience limite, or 'limit-experience', a driving, luxurious expenditure of energy that pushes against sensory boundaries. Translated into varying types of physically-infused aesthetic expressions, this decadent limit-experience is a subversive mode that deconstructs and challenges both audience sensibilities and popular standards of taste. Volume 
XI of Moveable Type explores this intersection of excess, subversion and deconstruction through various iterations of decadence across different texts and time periods.

We begin with a visual example to demonstrate what is meant by a decadent limitexperience—in this case, the cover image of this journal. Viewing Gustave Moreau's Jupiter and Semele is an immersive sensory experience. Confrontational in its excess, yet alluring in its opulence, and unapologetic in its sensualism, Moreau's masterpiece is a visual embodiment of a decadent ethos. Moreau's painterly subjects generally pertain to mythology, and employ static compositions that echo his early education in Renaissance paintings, as well as his immediate Neoclassical forebears such as Jacques-Louis David. Certainly Moreau, a Symbolist, might seek to differentiate rather than align his artistic style with the decadence with which it is so often identified. But regardless of the niche categorizations of fin-de-siècle painters, Jupiter and Semele provides a valuable case study in translating decadent energy to cultural artefacts. It is less the type of historicized mythology painting typical of Moreau's oeuvre than it is a uniquely cathartic moment of excess. The chaotic energy of a decadent artistic credo does not quietly pervade, hint, or wink from the background; rather, it revels across the canvas in a cavalcade of extravagant spectacle. Richly hued and indulgent in its abundance, the painting is a cornucopia of luminescent forms. That energy is transmitted to the viewer, disorienting the eye so that it must always move in search of focus, and is never quite certain of where to land. Whenever the eye does rest at any given moment, it is only to discovers more and more ornate details emerging from their obscured recesses.

Given Moreau's background in emulating Renaissance masters, it is intriguing and revelatory that he should bypass Doric austerity and Ionic elegance, opting instead for an orgiastic Roman feast for the eyes. To specify but a few elements: Classical allegories and mythological figures abound, not in silent marble friezes as is their traditional wont, but stacked in the dramatic shadows of a stage-like foreground. Corinthian columns form the central architecture of a grandiose, quasi-Baroque set-piece. Luxuriant vegetation, both the organic and the carvings on the columns' capitals pervade the framework of the painting; nature is present, yet moulded by stagecraft. Semele's physicality is highlighted by a pallor that contrasts with the richly hued adornments of the other bodies, and draws attention to a living, breathing sensualism. This contrast draws attention to her upward gaze, which in turn emphasizes the towering excess upon which Jupiter sits enthroned. The vertical composition radiates with potential for upward optical motion; yet, somewhat anticlimactically, the potential is never acted upon. Instead, the visual energy 
remains concentrated in the earthy, grounded physical forms below. It is at this location that we come to the decadent moment that underpins this collection of critical essays.

As it has been mentioned, decadence, in both its literal etymological sense as well as a critical term employed in socio-political and artistic contexts, refers to a 'decline'. Distilled from its defining texts such as Joris-Karl Huysman's $\grave{A}$ rebours (1884) and Oscar Wilde's The Picture of Dorian Gray (1890), decadence can be further translated as an active descent that pulls into physicality, away from transcendence, and into earthly embodiment. It is deposition, as opposed to sublimation. Moreau's Jupiter and Semele is an invaluable visual illustration of this tension between upward and downward motion; potential and kinetic energy; and bodied and disembodied sensory experiences. This study in excess, with its barrage of visual details, is an endurance exercise on the part of the viewer. The limits of perception are tested as the eye scans for focus and comprehension of the multitude of visual elements presented. Herein lies the locus of the decadent limitexperience, as well as the critical focus of this volume. Through different media and time periods, the essays in this collection set forth diverse perspectives on permutations of the decadent limit-experience through a variety of texts, ranging from literature and film to new directions in academic discourse. Employing diverse interpretations of decadence, this volume sets forth variations on familiar themes, and proposes new possibilities in the application of an evocative critical term that is simultaneously localized to a specific artistic epoch, yet teems with far-reaching ideas and texts beyond its fin-de-siècle associations.

In a collection of essays discussing limits and excess, it is fitting that the Marquis de Sade should loom large. Rebekkah Dilts' study of sadomasochistic themes in the novels of Rachilde (sometimes called the 'queen of decadence') examines the portrayals of gendered power dynamics and unfettered physicality in Monsieur Venus and La Marquise de Sade. Drawing from Gilles Deleuze's Masochism: Coldness and Cruelty, Dilts delivers a rich close reading of Rachilde's erotic aesthetics and a valuable perspective on amoral (anti-)heroines. Can Rachilde's female libertines, following in the tradition of Sade's Juliette, be considered 'feminist', a label that Rachilde herself rejected? Or do Sadean heroines and their descendants present an alternative category that could be useful in a twenty-first century cultural context?

Continuing in a Sadean vein, Ray Huling's fascinating and innovative essay on 'Bataillean ecology' uses Georges Bataille's biography and his writings about consumption, both of surplus food and energy, as a locus for new theories of 'sustainable excess'. 
Synthesizing across disciplines, Bataille's biographical fascination with Sade, discussed through accounts of his unconventional dinner parties, is juxtaposed with environmental concerns about achieving a sustainable biosphere. The result is a new perspective on conscious modes of consumption, and a reassessment of how theories of limit-experience and decadent energy can translate to practical applications.

Following these Sadean preludes, we move forward to 1970s cinema. James Jackson's close reading of James Bidgood's arthouse film Pink Narcissus (1971) is a fascinating perspective on the surreal story-telling and sumptuous visuals that depict the fantasies and life of a male prostitute named 'Pan' in late-1960s Manhattan. Guiding us through the protagonist's dreamscapes, which feature Classical allegory, vivid colours, and odes to masculine beauty, Jackson posits that Bidgood's filmmaking allies camp imagery with nature, rather than setting them in polar opposition, as a means of rejecting hostile contemporary attitudes toward homoeroticism. Jackson deconstructs the aesthetic contrast between the gritty danger of Pan's real life and the lush world of fantasy in which Pan esconces himself, discussing this in relation to the filmmaker's social context, where the veneer of beauty and dreamlike visuals belie the threats of a hostile urban landscape.

This stateside exploration of spectatorship continues with a leap forward by twentyfive years into a starkly different context—the 1996 Republican National Convention. Dr. Stephen Newton deconstructs the idiosyncrasies of an obscure politician in a wry examination of public spectacle and the performative Americana of political campaigns in the United States. The employment of excess and sensory engagement as a political strategy comes to the fore in this humorous critical account on a surreal moment in American political history.

The preceding foray into decadence within the twentieth-century American cultural context finishes with Dr. Larry Shillock's essay on Raymond Chandler's 1939 novel The Big Sleep. An intriguing investigation into the role of the femme fatale and the rampant pursuit of bodily sensation in catalysing characters' mental and physical deterioration, Shillock's interpretation of decadence focuses on the literal sense of the word ('decline'), narrating the trajectory of familial degeneration that Chandler portrays in his seminal hardboiled crime novel. Juxtaposing the novel with works like Oscar Wilde's The Picture of Dorian Grey and Joris-Karl Huysmans $\dot{A}$ rebours, the article traces their influence through the plot of the novel, presenting a rich and insightful perspective on the decadent heritage of a crime fiction classic.

Finally, Ali Zamanpour's close reading of Rawi Hage's Carnival brings this exploration of decadence up to the contemporary moment, forwarding possibilities for 
reading decadent themes in new literary contexts. Zamanpour asserts that Hage's depiction of 'creatureliness' in the dystopian urban landscape of his 2013 novel reimagines the cosmopolitan as a bodied location that breaks down distinctions between humans and animal. Identifying various loci of social critique, Zamanpour takes us through an alternative perspective on decadence within an utterly new location-a postapocalyptic cityscape where marginalized anthropomorphic bodies expend energy to survive, dream of class rebellion, and envision possibilities of physical and mental transport.

This exploration of decadent themes closes with reviews of four recent critical works. These include Katie Arthur's review of Unwatchable (2019), an anthology of scholarly writing about viewership and spectacle, and Kimberley Challis on the transnational decadence discussed in Robert Stilling's Beginning at the End: Decadence, and Postcolonial Poetry (2018). Dr. Kay J. Walter considers the reclamation of cultural memory in Francis O'Gorman's Forgetfulness: Making the Modern Culture of Amnesia (2017), and, in closing, Christopher Webb discusses political economy and idleness in Richard Adelman's Idleness and Aesthetic Consciousness, 1815-1900 (2018).

Through this array of texts and critical perspectives from different time periods, media, and cultural landscapes, Volume XI of Moveable Type proffers an eclectic perspective on the familiar literary term that is decadence. Unifying these individual points is the bodied aesthetic experience that underpins the decadent ethos-the same luxuriant energy that Moreau so aptly illustrated in Jupiter and Semele. This collection of essays shows decadence to be not just a historical moment, but also a site of multiplicity and excess where the senses are tested, sometimes broken, but always marked by stimulation. Within this nexus of physicalized energy, one encounters polarities vibrating with tension and potential motion — fascination coupled with disgust, awe warring with disbelief, and sensory engagement accompanied by synaptic fatigue. Through examining different critical interpretations of decadence, this issue of Moveable Type seeks to propel the decadent moment into new regions of aesthetic discourse, from its nineteenth-century home through modern critical frontiers.

Sarah-Jean Zubair (Editor, Moveable Type) Department of English Language \& Literature University College London 